during the time she was in the hospital. Widal's reaction was not obtained. The pulse was 120, quick, and of low tension. The bowels were opened on an average six times a day. The motions were liquid and offensive and contained frecal matter with a good deal of blood and but little mucus. There was romiting but rarely more than twice a day and mot every day, the vomited matter being green in colour. The patient was very weak and looked pale and wasted. There was no pain and she complained of nothing but the diarrhøea and general weakness. The torgue was pale, moist, and slightly furred. The appetite was gond and she frequently asked for solid food. There was no abdominal distension and no tenderness could be detected. The liver and spleen were not palpable. A soft apical systolic murmur was heard but it was not conducted into the axilla. The treatment consisted of hypodermic injections of morphine with enemata of opium. The patient gradually sank, the temperature fell to $96^{\circ}$, and she died on May 7 th after an illness of about five weeks' duration. No necropsy was obtained.

Remarks by Dr. MurRELL. - It is probable that all five of these cases are examples of ulcerative colitis, although in only two of them was the diagnosis confirmed by necropsy. The general course of the symptoms and the high rate of mortality confirm this view. Ulcerative colitis is by no means a common disease, at all events in London. I have consulted the records of the hospital and find that in 19 years, from 1884 to 1902 inclusive, there were only 15 cases, 11 in men and four in women, and of these there died five men and two women. In one of these cases, that of a man, aged 26 years, there were abscesses of the liver which after perforating the diaphragm opened into the lung and were partially evacuated through the bronchi. It is probable from the report of the necropsy that this was in reality a case of colitis dysenterica and should not be incladed in the list. That would give 14 cases of ulcerative colitis in 19 years with a mortality of 40 per cent. in the men and 50 per cent. in the women Including the present five cases we get a mortality of 46 per cent. in the men and 66 per cent. in the women.

The term " alcerative colitis" or "simple ulcerative colitis" is admittedly a bad one, sanctioned only by long use, for alceration of the large intestine may be dysenteric, tuberculous, or malignant in origin and is not uncommon in enteric fever. Considerable difficulty exists in distinguishing between different forms of inflammatory diseace affecting the colon and post mortem it is impossible from an insfection of the large intestine alone to discriminate between ulcerative colitis and chronic dysentery. The clinical features of the disease, however, are sufficiently characteristic. Respecting its origin and causation little is known. It attacks both sexes but appears to be commoner in men than in women, for of 28 cases recorded at Gay's Hospital 15 were in men and 13 in women, whilst of the 19 cases at the Westminster Hospital 13 were in men and six in women, giving a total in 47 cases of 28 men and 19 women. The majority of cases occur between the ages of 20 and 30 years, but one of our cases was a boy aged 13 years. The onset is insidious, there is no rigor, and nothing in the early stage to distinguish it from an ordinary attack of diarrhoea. Pain is not a prominent symptom and as a rule there are no tormina nor is there tenesmus. No cause is as a rule assigned by the patient, although in one instance it is said to have followed an attack of enteric fever. One of our patients was in the habit of eating large quantities of a sweetmeat known as milk chocolate and the possibility of the disease having commenced as a tyrotoxicon infection was considered but there was nothing to support that view. The temperature was in most cases persistently high, whilst in others it was little above the normal. As a rule it was subnormal during the last 48 hours of life. In some cases vomiting was persistent, whilst in others it was absent or of rare occurrence. In all cases the patient rapidly lost weight and displayed signs of great weakness. There was little or no mental depression and most of the patients were checrful to the end. There was no loss of appetite and a constant desire was expressed for more food and often for some particular article of diet. The diarrhcea was always the prominent feature and in most cases it was practically unceasing. The microscopical examination of the fæces gave no uniform result. In one instance the motions consisted of an almost pure culture of streptococci and it was thought that injections of anti-streptococcic serum might be indicated, but on the following day without any apparent reason the streptococci disappeared and were replaced by a totally different organism. It has been suggested that the nlceration of the colon may be dne to an amoba but there is nothing definitely to support this view. Metastatic abscesses are rare and little or no change is found in the liver. It is said that the disease is associated in some way with kidney trouble but this is the exception and not the rule.

The post-mortem appearances present considerable uniformity and in both our cases there was a condition of ulcerative colitis throughout. In Dr. W. H. Allchin's classical case recorded in rol. xxvi. of the Transactions of the Pathological Society of London-the specimen is in the museum of the Westminster Hospital-there were in the ascending and transverse colons numerous circular punched-out ulcers varying in size from that of a threepenny-piece to that of a florin. In another case at the hospital, that of a woman, aged 50 years, the mucosa of the colon from the splenic flexure to the anus was extensively ulcerated, the remaining ragged mucosal areas being much thickened. The vermiform appendix is not infrequently involved and in one case it was glued to the pelvic brim by soft adhesions. It contained a fæcal calculoid of about the size of a grape-stone and from a minute aperture at the apex there was exudation of pus.

The duration of the disease is variable and in some cases it may extend over a period of three or four years. The treatment is essentially unsatisfactory ; in our cases almost every drug or combination of drugs likely to be of use was tried, with the exception of injections of nitrate of silver, and they all failed. Whether surgical interference is likely to be more successful it is difficult to say. The operation commonly proposed is that of establishing an anastomosis between the ileum and the lower end of the colon, and failing this a right-sided colotomy. The operation performed by Mr. Spencer promises well, although in this particnlar case from unforeseen difficulties it was not successful. Continuous irrigation of the bowel either with plain water or boric acid solution is probably the key to the situation.

\section{ROYAL SOUTHERN HOSPITAL, LIVERPOOL.}

A CASE OF SPONTANEOUS PERFORATION OF THE INTRAPERICARDIAL POR'TION OF THE INEERIOR VENA CAVA.

(Under the care of Mr. I. McW. BouRKE, late house physician.)

THE patient, a man, aged 60 years, was taken into the Royal Southern Hospital at 2 A.M. on a police ambulance. He had been seen to fall suddenly while walking along the street. Mr. Bourke saw him immediately after admission. He was lying on the ambulance talking very volubly but would tell nothing about himself except that he had been drinking. On examination there were no signs of injury. The pulse and respirations were quite quiet and the tension of the former was goor. The patient ex pressed a desire to micturate and there being nothing in his condition to cause alarm he was allowed to do so. As the man lived close by Mr. Bourke arranged with the police to take him home. He was called five minutes later just as the patient was leaving and found him ccmpletely collapsed; he died in five minutes.

Necropsy. - At the post-mortem examination rigor mortis and post-mortem hypostasis were marked. There was some cyanosis of the head and the neck. In the right and left pleuræ there were old adhesions, these being scattered irregularly in the left. No fluid was present. Old scars wtre present in both apices of the lungs which were a little emphysematous. The left ventricle of the heart was hypertrophied and dilated. The pericardium was full of blood and two large masses of blood clot were causing considerable distension of the pericardial sac. At the anterior part of the inferior vena cava on lifting up the heart there was present a round patch where the tunica adventitia and part of the tunica media were absent, resembling a form of ulcer. The margins were not indurated nor was the surface of the patch ulcerated or sloughy; simply the tunica intima lay exposed, the patch being surrounded by no defnite margin and the three layers gradualiy merging cne into the other. In the centre of the patch there was a small perforation into the inferior $v \in$ na cava which was 
the cause of death. Two similar patches were present, one on the lower branch of the left pulmonary vein and the other on the posterior part of the pulmonary artery. The pericardium, apart from these erosion-like ulcers, was healthy. There was marked atheroma in the aorta, many patches being calcified. The liver was fatty with a thickened capsule. There were no adhesions. Its substance was soft and friable. The pulp of the spleen was somewhat fibroid; its capsule was thickened. There were signs of old perisplenitis. Nothing abnormal was found in the alimentary system. There were signs of early cirrhosis in the kidnzys. The bladder, ureters, and suprarenals were normal.

Remarks by Mr. BouRKE.-If the perforation had occurred a few minutes later the patient would have died in the street. This would have been an unfortunate occurrence which I do not think one could have foreseen. I venture to publish this case as I have never come across a similar one neither can I find any record of such a case. I am indebted to Dr. J. Lyn Dimond, pathologist to the hospital, for the post-mortem notes of the case.

\section{atterical Sorieties.}

\section{ROYAL MEDICAL AND CHIRURGICAL SOCIETY.}

\section{The Cardiac Dulness in Cases of Cancer.-A Case of} Properitoneal Hernia.

A MEETING of this society was beld on March 8th, Sir R. Douglas Powell, Bart., the President, being in the chair.

Dr. W. GoRDon (Exeter) read a paper on the Cardiac Dulness in Cases of Cancer. He said that some years ago be had noticed in cases of gastric cancer, in which ordinary emphysema could not be thought to exist, that the cardiac dulness was greatly reduced or obliterated in the recumbent posture. After observing this in many instances he had jightly diagnosed cuncer on the strength of it in five consecutive cases. Since then it had been noticed in many cases. (The normal cardiac dulness in the recumbent posture was not the same as in the erect posture. The absence or reduction of the dulness in cases of cancer was looked for in th 3 recumbent postare only.) The following was a summary of rasults. Reduction or loss of cardiac dulness was common in caies of cancer, especially in case of abdominal cancer towards their end. It was not, how. ever, always present. It might precede cachexia, marked wasting, and loss of skin elasticity, bat seemed absent in the earliest stages. If absent at first it might slowly develop towards the end It might be found, but apparently rarely, in other diseases and it did not seem to occur in cases of sarcoma When present in a doubtful case its presence was very suggestive of the existence of a cancer. When absent in a doubtful case of considerable duration it was slightly suggestive that the case was not one of cancer. In assessing the value of this physical sign it was of course necessary to exclude the existence of all ordinary causes of alteration of the area of cardiac dulness. The explanation appeared to be that the margins of the lungs extended across the front of the heart (this was found post mortem to be the fact) owing to a loss of elasticity in their substance similar to the loss of elasticity often observed in the abdominal skin in many cases of abdominal cancer.-The PrEsident said that Dr. Gurdon had in his caces been most careful to exclui e the diminution of the cardiac dulness such as might be due to emphysema of the lung, retraction of the heart, or to atrophy of the heart itself. The explanation given was that absence of cardiac dulness was due to a change in the lang tissue. He asked if any microscopical examination had been mide of the atrophic lung tissue and if any change $h$ ad been found. He suggested the importance of examining a large series of cawes or cancer in order to find out in what proportion of caves this sign was present.-Dr. H. S FRENCg asked whether Dr. Gordon laid stress on the absence of cardiac dulness when the case was first seen or only when the cardiac dulners disappeared under observation -Dr. GORDON replied that he had examined the lung of one case wicroscopically but had heen unable to demonstrate any change. He was of opinion that the loss of elasticity was a condition which could not be demonstrated by microscopical examina tion. Both the initial absence of the cardiac dulness and its disappearance under observation were important.

Mr. H. Betham Robinson read an account of a case of Properitoneal Hernia. He said that the patient, who had been the subject of left inguinal hernia for some years, was admitted into St. Thomas's Hospital with symptoms of obstruction of three days' duration. There had never been any difficulty in reducing the hernia and on admission there was no evidence of a hernia. Abdominal section was performed and a loop of small gut and matted omentum were found entering through a small opening into a pouch situated behind the left side of the lower part of the abdominal wall at the side of the bladder. On dividing this ring the congested and matted omentum could be withdrawn but not so the bowel which was firmly adherent to the sac. On opening up the inguinal canal the bowel presented at the normal site of the inner ring. The bowel here was quite black and lacerated easily on attempted separation. It was evident that the gut occupied and was strangulated in, a pouch behind the abdominal wall and that it was gangrenous. Having packed round the inner opening with gauze the gat was separated from the sac withdrawn through the inner opening, and brought out externally. Four and a half inches of gut were rezected and an end-to-end junction was made. The patient died somewhat suddenly four hours after the operation. A careful necropsy showed that there was a bilocular sac; an inguinal pouch extended through the canal to the external ring imbedded in the elements of the cord; the testis was normally placed. This inguinal sac communicated by a small opening with another sac deeply placed behind the abdominal wall in the subperitoneal tissue; this inner sac was of an oval form and reached from the side of the bladder outwards into the iliac fossa. Its small inner opening in which the gut had been strangulated was the true internal ring. The case was thus a typical example of a properitoneal hernia, as described by Kronlein and Breiter. It differed, however, from the majority described by them in that the testis had properly descended but from the relation of the sac to the elements of the cord there was little doubt that the sac was a patent funicular process which had undergone dilatation in such a manner as to assume the bilocular form.Mr. W. MCAdAM ECCLES said that it was necessary to distinguish between the properitoneal and the interstitial form of inguinal hernia. He mentioned the great preponderance of the properitoneal variety in the male subject and said that it was his belief that this form only occurred in males. The interstitial variety, however, was proportionately more common in females. Probably in most if not all cases of properitoneal hernia there was some congenital difect in the descent of the testis and he asked if the testes on the two sides in Mr. Robinson's case were of the same size. The production of the interstitial hernia was often due to the blockage of a small external abdominal ring by a testis; the descent of viscera into the accompanying processus vaginalis caused dilatation of the peritoneal pouch in an upward and outward direction in a plane of the abdominal wall in front of the transver ralis fascia. In many cases of interstitial hernia there was no prolongation of the sac into the scrotum. He suggested the importance of exploration in all cases of imperfectly descended testis accompanied by a definite hernia.-Mr. ROBINSON, in reply, said that a crural form of properitoneal hernia did occur in females. In his case the testes were normal.

\section{EDINBURGH MEDICO-CHIRURGICAL SOCIETY.}

Exhibition of Cases.-Electric Currents of High Frequency.Chronio Intestinal Obstruotion.

A Meetisg of this society was held on March 2nd, Professor JoHn CHIENe, the President, beirg in the chair.

Mr. H. J. StILES showed an infant after Ligature of Both Common Carotid Arteries for Chronic Hydrocephalus. The vessels were ligatured at an interval of two weeks in order to cut off the blood-supply to the plexuses and no mental disturbance ensued from the great limitation of the supply. The operation was completed nine weeks previously and the head bad only undergone an enlargement of a quarter of an inch.

Dr. D. CHALMERS W ATSOS showed a woman suffering from 